\title{
editorial
}

\section{Address bias}

W

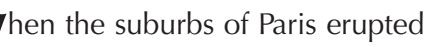
in violence in 2005, many commentators were quick to blame the riots on the growing frustration among French youths. Indeed, a home address in the banlieue can automatically diminish their chances in the job market. This type of discrimination occurs in many other countries and in many different contexts, not just when it comes to finding a job. But what does this have to do with science? It sounds like a social problem that politicians need to solve. However, I suggest that scientists discriminate in a similar way by judging colleagues on their work address, which subtly influences how careers progress.

Many years ago, I was part of a selection committee-not at EMBO-for international fellowships to promote mobility. Among the applicants was a scientist who wanted to move from the UK to Spain. The UK representative on the panel was quite enthusiastic when he thought that the applicant wanted to move to the UK. As soon as his error was pointed out, he immediately became more critical of the application-obviously, the address and not the quality of the application was the reason for this change of opinion. This is not a unique occurrence: time and again, scientific committee members demonstrate their narrow appreciation of researchers in other countries when they propose only their neighbours as committee members or speakers at meetings. As a result of this subtle process of discrimination, doors close and old boys club together.

This is not limited to scientists; politicians are also victims of address bias. How else would one explain their calls for 'iconic' institutes where the name alone seems to imply quality? Indeed, the creation of a European Institute of Technology was driven initially by concerns that Europe did not have something as readily identified as the Massachusetts Institute of Technology. Many scientists, politicians and administrators recognize Harvard, Stanford or Yale and immediately believe that their research must be top notch, but there is no similar response to institutes in Heraklion, Szeged or Tübingen-although they too have excellent scientists doing high-quality research. Thus, when a decision must be made, applicants from wellknown cities have a slight advantage because their work address does not raise the question "where on earth is that?" even if the institute itself is unknown.

The impact of address bias is even larger when it comes to publications. After all, our careers hinge not only on the quality of our research but also on where we publish it. Any bias caused by the address of the author can therefore have a major effect on their career prospects and, by extension, on the ranking of science in their country. When a paper lands on the desk of a referee or an editor, does a Zhang working in Berkeley have a head-start on a Zhang working in Beijing? Does the location of the laboratory factor into our acceptance of the data? I suspect that an address that is associated with high quality sends a positive message, even if we have never heard of the author. There is logic to this-good institutes usually attract and select very good scientists, after all. But the reverse situation-in which an author's work is doubted because he or she works in an unfamiliar institute-is an unacceptable form of prejudice. We all deny any bias, but the fact is that our immediate reactions are often governed by subliminal aspects-thus, the address of the first or last author is not always a neutral piece of information when assessing a paper.

Address bias is also obvious in the recent debate on how to weed out fraudulent research. When the scientific community discussed steps to avoid a repetition of the Hwang case, an implication arose that such wrongdoing was inevitably more likely in South Korea than in, say, South Carolina. Similar insinuations-that moral and ethical standards in some countries are lower than those in Europe or North America-appear regularly despite some of the most noted cases of fraud arising in respected locations. Perhaps researchers are policed more rigorously in these places, but that should not suggest that fraud occurs unlimited elsewhere.

This geographical bias is ironic, given that scientists pride themselves on the truly international nature of their business. However, if we really understand science as a global enterprise, we must assess and accept new developments, ideas and colleagues equally, no matter from where they come. Ideally, someone's working address - whether on a grant application or a submitted manuscript-should make no difference. Hopefully, this editorial will place a corrective message into the subconscious by drawing attention to address bias and its implications, even if we verbally deny that there is such a problem.

\section{Frank Gannon}

doi:10.1038/sj.embor.7400972 